\title{
PROPAGAÇÃO DA PITANGUEIRA ATRAVÉS DA ENXERTIA DE GARFAGEM ${ }^{1}$
}

\author{
RODRIGO CEZAR FRANZON² ${ }^{2}$ RAFAEL DA SILVAGONÇALVES ${ }^{3}$, LUÍS EDUARDO CORRÊAANTUNES ${ }^{4}$, \\ MARIA DO CARMO BASSOLS RASEIRA ${ }^{4}$, RENATOTREVISAN $^{5}$
}

RESUMO - A pitangueira é uma frutífera nativa com potencial para exploração comercial. Entretanto, os métodos de propagação mais comuns não são satisfatórios para a multiplicação desta espécie em larga escala. O objetivo do trabalho foi o de avaliar o uso do método de enxertia de garfagem no topo, em fenda cheia e dupla fenda, bem como a melhor época para a realização desta prática (julho, agosto e setembro), nas condições do Sul do Brasil. O experimento foi conduzido no ano de 2005, na Embrapa Clima Temperado, Pelotas-RS. O delineamento foi o inteiramente casualizado, em esquema fatorial 2 x 3 (tipo de garfagem x época de enxertia), com 5 repetições. Conclui-se que a enxertia de garfagem no topo, em fenda cheia e/ou em dupla fenda, pode ser utilizada para a propagação vegetativa da pitangueira durante o inverno, sendo que a enxertia de garfagem em fenda cheia proporcionou melhores percentuais de pegamento dos enxertos $(60,0 \%)$ do que a garfagem em dupla fenda $(44,2 \%)$. Quanto à época, os melhores percentuais foram obtidos no mês de setembro, com $67,5 \%$ de pegamento dos enxertos, seguido pelo mês de agosto e julho, com $51,3 \%$ e $37,5 \%$, respectivamente. Termos para indexação: Eugenia uniflora; Myrtaceae; Propagação vegetativa.

\section{SURINAM CHERRY PROPAGATION BY MEANS OF GRAFTING}

ABSTRACT- The Surinam cherry is a native fruit from Brazil with a great potential for commercial production. However, the common clonal propagation methods have not given a high percentage of success. The present work had the aim to test the use of two types of grafting: cleft graft and wedge graft as well as the best time to use this technique (July, August and September), under Southern Brazil conditions. The experiment was carried out at EMBRAPA Clima Temperado, in Pelotas, RS, in the year of 2005. The experimental design was completely randomized arranged as a $2 \times 3$ factorial plan (type of grafting $x$ time), with 5 replications . It was concluded that both types of grafting could be used, during the winter time, for asexual propagation of Surinam cherry. Cleft grafting had the highest percentage of survival $(60 \%)$ when compared to the wedge grafting $(44.2 \%)$. The highest percentage of grafting success was obtained in September with 67.5\%, followed by the months of August and July, with 51.3\% and 37.5\%, respectively.

Index terms: Eugenia uniflora; Myrtaceae; Vegetative propagation.

\section{INTRODUÇÃO}

A pitangueira (Eugenia uniflora L.) é uma mirtácea frutífera com grande potencial para exploração econômica, principalmente em nichos de mercado ávidos por novidades. Esta espécie é originária da região que se estende desde o Brasil Central até o norte da Argentina, sendo que sua distribuição se fez ao longo de quase todo o território brasileiro, bem como em várias partes do mundo (Bezerra et al., 2000; Donadio et al., 2002).

Além da possibilidade de exploração para consumo in natura, os frutos da pitangueira podem ser utilizados pela agroindústria para o fabrico de sucos, sorvetes, bebidas lácteas, geléias, doces, licores e outros produtos. Esta espécie, bem como outras espécies nativas, também vem despertando a atenção da indústria farmacêutica, pois as frutas são ricas em vitaminas e em substâncias antioxidantes, dentre outras, como óleos essenciais que podem ser extraídos das folhas e de outras partes da planta (Marin et al., 2004).

No Sul do Brasil, a Embrapa Clima Temperado-CPACT, em Pelotas-RS, vem realizando estudos com algumas frutíferas nativas da região, com a finalidade de introduzi-las em cultivos comerciais. Dentre as espécies estudadas, a pitangueira, juntamente com o araçazeiro, é a que apresenta maior potencial para cultivo, pois existem trabalhos adiantados de seleção de clones, que devem ser testados para verificar as possibilidades de serem propagados como cultivares comerciais (Franzon et al., 2004).

Da mesma forma, clones com elevado potencial produtivo e boas características agronômicas foram selecionados no Estado de Pernambuco, onde trabalhos com a espécie vêm sendo realizados pela Empresa Pernambucana de Pesquisa Agropecuária - IPA, em Itambé, na região da Zona da Mata (Bezerra et al., 1995; Bezerra et al., 1999).

Porém, para maiores avanços, é necessário encontrar alternativas viáveis para a propagação vegetativa da espécie, pois um dos principais problemas encontrados para a expansão do cultivo é a produção de mudas. A propagação por sementes, atualmente o método mais utilizado para a produção de mudas desta mirtácea, apresenta como inconvenientes a grande

1(Trabalho 041-07). Recebido em: 27-02-2007. Aceito para publicação em: 07-01-2008.APOIO: FAPERGS.

${ }^{2}$ Eng $^{\circ}$. Agr ${ }^{\circ}$. MSc., aluno do Curso de Pós-graduação em Agronomia, área de concentração em Fruticultura de Clima Temperado, UFPel, Pelotas-RS. Bolsista CAPES. E-mail: rcfranzon@hotmail.com.

${ }^{3}$ Aluno do Curso de Agronomia, UFPel, Pelotas-RS. Bolsista FAPERGS. E-mail: rsgagro@pop.com.br.

${ }^{4}$ Eng $^{\circ}$. Agr ${ }^{\circ}$. Dr., Pesquisador Embrapa Clima Temperado/CPACT, Pelotas, RS. Bolsista CNPq-PQ. E-mail: antunes@cpact.embrapa.br, bassols@cpact.embrapa.br.

${ }^{5}$ Eng $^{\circ}$ Agr $^{\circ}$ Dr., Prof. UFSM/CAFW, Frederico Westphalen-RS. E-mail: renatrevisan@gmail.com. 
variabilidade entre as plantas e também na produção, frutificação baixa e mais tardia, qualidade de frutos, entre outros.

Por outro lado, a propagação clonal proporciona a formação de pomares uniformes, com populações de plantas homogêneas. No entanto, são raras as referências sobre métodos viáveis de propagação vegetativa da pitangueira.

No Brasil, alguns trabalhos com propagação vegetativa da pitangueira, através de enxertia, vêm sendo conduzidos no Estado do Pernambuco, onde existem áreas de plantio comercial, e a importância econômica da espécie vem crescendo (Bezerra et al., 1999; Bezerra et al., 2002). Estes autores recomendam a utilização da enxertia por garfagem na propagação da pitangueira, devido ao menor tempo para a formação da muda.

A enxertia por garfagem, em espécies frutíferas propagadas comercialmente no Sul do Brasil, normalmente é realizada no período de repouso vegetativo, principalmente nos meses de julho e agosto (Fachinello et al., 2005). Entretanto, sabe-se que cada espécie pode responder de diferentes formas à época de realização da enxertia, ocorrendo diferenças até mesmo dentro da mesma estação do ano. Para o Sul do Brasil, não foram encontradas referências ao estudo da propagação vegetativa da pitangueira.

Em plantas lenhosas, à medida que o diâmetro do tronco aumenta, maior é o estado de lignificação do lenho e maior é a dificuldade de cicatrização e união entre enxerto e porta-enxerto. Outro problema, especialmente em espécies da família Myrtaceae, é a oxidação de compostos fenólicos, que dificulta a formação do calo e o processo de cicatrização (Fachinello et al., 2005). Em função disto, opta-se pela utilização de porta-enxertos mais jovens e com diâmetro reduzido, ou seja, menos lignificados e menor atividade de oxidação. No caso de plantas muito lignificadas e com alta atividade de oxidação de compostos fenólicos, como a pitangueira, pode-se optar pela realização da enxertia em portaenxertos com diâmetro de 2 a $4 \mathrm{~mm}$, na região do enxerto. Utilizando-se de um porta-enxerto mais juvenil, as células do parênquima estarão menos lignificadas, e menor será a reação de oxidação, o que poderá facilitar o processo de união e pegamento do enxerto.

Neste contexto, o objetivo do presente trabalho foi o de avaliar o uso do método da enxertia por garfagem no topo, bem como verificar qual a melhor época para a realização desta, durante o inverno, nas condições do Sul do Brasil.

\section{MATERIAL E MÉTODOS}

O experimento foi conduzido no ano de 2005, na Embrapa Clima Temperado-CPACT, localizada em Pelotas-RS.

Foram utilizados garfos com aproximadamente $5 \mathrm{~cm}$ de comprimento e contendo um par de gemas, onde foram mantidas as duas folhas, cada uma delas reduzidas em $50 \%$ de sua área foliar. Ressalta-se que, mesmo nas condições de inverno da região Sul do Brasil, as plantas de pitangueira não perdem suas folhas. Os garfos foram coletados de ramos semi-lenhosos, oriundos do ciclo de crescimento anterior (setembro de 2004 a maio de 2005), de um clone com características agronômicas promissoras para ser testado e, talvez, propagado como cultivar, denominado PIT
15, mantido na coleção de seleções de pitangueira no CPACT. Para a obtenção de um maior número de ramos que pudessem ser utilizados para a coleta de garfos, foi realizada uma poda drástica em galhos da planta-mãe, em setembro de 2004, com o objetivo de estimular a emissão de novas brotações.

Utilizou-se, como porta-enxertos, plantas provenientes de sementes coletadas de plantas de pitangueira no CPACT. Estas foram semeadas em sacolas plásticas de coloração preta, medindo $8 \mathrm{~cm}$ de diâmetro e $15 \mathrm{~cm}$ de altura, contendo como substrato terra local misturada com areia, na proporção de 3:1.

Foram realizados dois tipos de enxertia de garfagem, no topo em fenda cheia e em dupla fenda (inglês complicado), a uma altura entre 30 e $40 \mathrm{~cm}$ do colo da planta. No ponto da enxertia, os porta-enxertos apresentavam, no momento em que foi feita a enxertia, diâmetro médio de $0,2 \mathrm{~cm}, 0,2 \mathrm{~cm}$ e $0,22 \mathrm{~cm}$, respectivamente, em cada época testada.

Foram testadas três épocas de enxertia, sendo estas: 06 de julho, 05 de agosto e 13 de setembro. Essas datas correspondem ao intervalo entre os dois ciclos de produção das plantas nas condições em que são mantidas no CPACT. Elas iniciam o primeiro ciclo de floração/frutificação em setembro, sendo que o mesmo se estende até dezembro, enquanto o segundo ciclo inicia em fevereiro e estende-se até maio (Franzon \& Raseira, 2004).

Foram mantidas as folhas existentes no porta-enxerto, abaixo do ponto de enxertia, a fim de manter a atividade fotossintética da planta até que houvesse a união dos tecidos do porta-enxerto e do garfo. Diferentemente, as brotações laterais existentes nesta região foram eliminadas, bem como aquelas que surgiram durante o acompanhamento do experimento.

Devido ao tipo de material utilizado, ambos (porta-enxerto e garfos) semilenhosos e frágeis ao manuseio, a enxertia foi realizada com o auxílio de bisturi, pois, para um perfeito contato entre as partes, torna-se necessário um corte uniforme. A amarração foi realizada com fita biodegradável para enxertia (parafilme).

Após a realização da enxertia, o enxerto (porta-enxerto + garfo) foi coberto com um saco tipo celofane $(18 \mathrm{~cm}$ x $30 \mathrm{~cm})$, no qual se fez um corte de $2 \mathrm{~cm}$ em uma das pontas superiores, a fim de formar uma câmara úmida para evitar a desidratação dos tecidos. O saco plástico foi amarrado a uma distância de 15 a 20 $\mathrm{cm}$ abaixo do ponto de enxertia. As plantas foram mantidas em casa de vegetação.

O delineamento foi o inteiramente casualizado, em esquema fatorial $2 \times 3$ (tipo de enxertia $\times$ época de enxertia), com 5 repetições, sendo a unidade experimental constituída por oito plantas.

Foram observadas as percentagens finais de brotação e de pegamento dos enxertos. O experimento foi acompanhado semanalmente, sendo considerados brotados aqueles que apresentavam brotações com início de expansão do primeiro par de folhas. Nesse momento, também foi feita a retirada dos sacos plásticos. A percentagem final de pegamento dos enxertos foi avaliada aos 110 dias após a instalação do experimento, considerando-se, para efeito de avaliação, apenas os enxertos sobreviventes. 
Os dados foram submetidos à análise de variância e comparação de médias, pelo teste de Tukey $(\mathrm{p}=0,05)$, sendo estas realizadas com auxílio do programa SISVAR (Ferreira, 2000). Para análise estatística dos resultados, os dados originais,em números de brotação e de pegamento dos enxertos, foram transformados $\operatorname{para} \sqrt{\mathrm{x}+0,5}$.

\section{RESULTADOS E DISCUSSÃO}

Não houve interação significativa entre os fatores estudados, tipo de garfagem e época de enxertia. Os percentuais de brotação não diferiram entre si nos diferentes tipos de enxertia realizados. Porém, houve diferenças significativas para os percentuais de pegamento dos enxertos (Tabela 1). Estes percentuais foram maiores para a enxertia de garfagem no topo em fenda cheia $(60,0 \%)$, comparativamente aos obtidos com a dupla fenda (44,2\%). Essa diferença pode estar relacionada com a maior facilidade e rapidez da realização da enxertia em fenda cheia e, conseqüentemente, menor exposição dos tecidos ao ambiente, o que reduz a reação de oxidação de compostos fenólicos. Devido ao tipo de material utilizado, porta-enxertos e garfos semilenhosos e com diâmetro médio de $0,20 \mathrm{~cm}$, os cortes na enxertia do tipo dupla fenda, bem como a amarração, foram mais difíceis de serem realizados.

Em relação à época de enxertia, houve diferenças significativas tanto para brotação como para pegamento dos enxertos (Tabela 1). Em ambos os casos, os melhores resultados foram obtidos no mês de setembro.

Mesmo não havendo interação significativa entre os fatores, vale ressaltar os índices de pegamento dos diferentes tipos de enxertia nas três épocas. Os índices foram de $42,5 \%$, $60,0 \%$ e $77,5 \%$ para a garfagem no topo em fenda cheia, contra $32,5 \%, 42,5 \%$ e $57,5 \%$ para a dupla fenda, nos meses de julho, agosto e setembro, respectivamente. Valores próximos aos encontrados no presente trabalho foram obtidos por Bezerra et al. (1999), que obtiveram percentuais de até $77,5 \%$ de pegamento em enxertia de pitangueira utilizando garfagem no topo em fenda cheia e à inglesa simples, e por Bezerra et al. (2002), com percentuais de até $81,5 \%$.

Os melhores resultados obtidos na terceira época, que corresponde ao mês de setembro, coincidem com a saída do período de inverno e também do período de dormência das plantas, nas condições do Sul do Brasil. Assim, estes maiores percentuais podem estar relacionados com o metabolismo das plantas, pois, na saída do período de frio e dormência, as plantas aumentam a atividade metabólica e a circulação de fotoassimilados, fazendo com que haja maior movimentação de reguladores de crescimento, o que pode auxiliar para o maior índice de pegamento. Desse modo, as células da região cambial, que possuem alta capacidade meristemática e que são as responsáveis pela união entre porta-enxerto e enxerto, devem ter tido seu processo de divisão e multiplicação acelerados. De acordo com Fachinello et al. (2005), a temperatura é um dos principais fatores envolvidos no processo da enxertia e, juntamente com a umidade, pode influenciar na taxa de divisão celular que afeta a formação de novas células, responsáveis pela união entre os tecidos envolvidos.

Com as condições apropriadas de umidade, proporcionada pela câmara úmida formada pelo saco plástico, e temperatura, provavelmente o período para a união entre as partes envolvidas, com a formação de tecidos vasculares, foi mais curto do que nas outras duas épocas (julho e agosto), onde a temperatura ainda era baixa, e as plantas encontravam-se com atividade metabólica menos intensa. Desse modo, supõe-se que, com o encurtamento do período para a formação dos novos tecidos vasculares, houve menor probabilidade de morte dos garfos por desidratação, esgotamento de reservas, ou ainda interferência de outros fatores que possam estar envolvidos. Segundo Hartmann et al. (1990), a rápida união entre as partes é fundamental para o sucesso da enxertia, pois diminui o período em que o enxerto poderia sofrer desidratação.

Os resultados obtidos no presente trabalho, nas condições do sul do Rio Grande do Sul, associados aos resultados obtidos por Bezerra et al. (1999 e 2002) na região de Pernambuco, Nordeste brasileiro, demonstram que a enxertia de garfagem no topo pode ser utilizada pela cadeia produtiva na produção de mudas de pitangueira de alta qualidade. Esta alternativa abre novas perspectivas para os trabalhos com essa frutífera nativa do Brasil, principalmente no Sul do País, onde até o momento não é utilizado um método adequado de propagação vegetativa. Assim, em breve, algumas seleções existentes no CPACT poderão ser testadas para serem propagadas como cultivares, proporcionando aos agricultores da região nova oportunidade de diversificação da produção e aumento na renda, principalmente na pequena propriedade familiar, forte característica no meio rural na região.

TABELA 1- Percentagem de brotação e pegamento dos enxertos (aos 110 dias), utilizando-se de dois tipos de enxertia de garfagem no topo, em pitangueira, em três épocas durante o inverno na região de PelotasRS. Pelotas-RS, 2005.

\begin{tabular}{lcc}
\hline Fator de variação & \% de brotadas* & \% de pegamento* \\
\hline Tipo de enxertia & & \\
Garfagem no topo em dupla fenda & $54,2 \mathrm{NS}$ & $44,2 \mathrm{~b}$ \\
$\quad$ Garfagem no topo em fenda cheia & 65,0 & $60,0 \mathrm{a}$ \\
\hline $\begin{array}{l}\text { Época de enxertia } \\
\text { 06 de julho }\end{array}$ & $41,3 \mathrm{~b}$ & $37,5 \mathrm{~b}$ \\
05 de agosto & $61,3 \mathrm{ab}$ & $51,3 \mathrm{ab}$ \\
13 de setembro & $76,3 \mathrm{a}$ & $67,5 \mathrm{a}$ \\
\hline Média geral & 59,6 & 52,1 \\
\hline Coeficiente de variação (\%) & 18,13 & 16,93
\end{tabular}

* Médias seguidas por letras minúsculas distintas na coluna, dentro de cada fator de variação, diferem estatisticamente entre si, pelo teste de Tukey $(\mathrm{p}=0,05) ; \mathrm{NS}=$ diferença não-significativa. 


\section{CONCLUSÕES}

1-A enxertia de garfagem no topo, em fenda cheia e/ou em dupla fenda, pode ser utilizada para a propagação vegetativa da pitangueira durante o inverno no Sul do Brasil.

2-A enxertia de garfagem em fenda cheia proporcionou melhores percentuais de pegamento do que a garfagem em dupla fenda, médias de $60 \%$ e $44,2 \%$, respectivamente.

3-Quanto à época, os melhores percentuais foram obtidos no mês de setembro $(67,5 \%)$, próximo à saída do inverno.

\section{REFERÊNCIAS}

BEZERRA, J.E.F.; LEDERMAN, I.E.; FREITAS, E.V.da; SANTOS, V.F.dos. Método de enxertia e idade de porta-enxerto na propagação da pitangueira (Eugenia uniflora L.). Revista Brasileira de Fruticultura, Jaboticabal, v.21, n.3, p.262-265. 1999.

BEZERRA, J.E.F.; LEDERMAN, I.E.; FREITAS, E.V.da; SILVA JUNIOR, J.F.da. Propagação de genótipos de pitangueira (Eugenia uniflora L.) pelo método de enxertia de garfagem no topo em fenda cheia. Revista Brasileira de Fruticultura, Jaboticabal, v.24, n.1, p.160-162, 2002.

BEZERRA, J.E.F.; LEDERMAN, I.E.; PEDROSA, A.C.; DANTAS, A.P.; FREITAS, E.V.de. Performance of surinam cherry (Eugenia uniflora L.) in Pernambuco, Brazil. Acta Horticulturae, Wageningen, n.370, p.77-81. 1995.

BEZERRA, J.E.F.; SILVA JUNIOR, J.F.da; LEDERMAN, I.E. Pitanga (Eugenia uniflora L.). Jaboticabal: FUNEP. 2000. 30p. (Série Frutas Nativas, 1).
DONADIO, L.C.; MÔRO, F.V.; SERVIDONE, A.A. Frutas Brasileiras. Jaboticabal: Ed. Novos Talentos, 2002. 288p.

FACHINELLO, J.C.; HOFFMANN, A.; NACHTIGAL, J.C. Propagação de plantas frutíferas. Brasília: Embrapa Informação Tecnológica, 2005.221p.

FERREIRA, D.F. Manual do sistema Sisvar para análises estatísticas. Lavras: UFLA, 2000. 66p.

FRANZON, RC.; RASEIRA, M.C.B. Características fenológicas e morfológicas, floração e maturação dos frutos de mirtáceas frutíferas nativas do Sul do Brasil. In: RASEIRA, M.C.B.; ANTUNES, L.E.C.; TREVISAN, R.; GONÇALVES, E.D. Espécies frutíferas nativas do sul do Brasil. Pelotas: Embrapa Clima Temperado, 2004. p.27-46. (Documentos, 129)

FRANZON, RC.; RASEIRA, M.C.B.; CORRÊA, E.R. Potencialidades agronômicas de algumas mirtáceas frutíferas nativas do Sul do Brasil. In: RASEIRA, M.C.B.; ANTUNES, L.E.C.; TREVISAN, R. e GONÇALVES, E.D. Espécies frutíferas nativas do sul do Brasil . Pelotas: Embrapa Clima Temperado, 2004. p.99106. (Documentos, 129)

HARTMANN, N.T.; KESTER, D.E.; DAVIES JUNIOR, F.T. Plant propagation: principles and practices. $5^{\text {th }} \mathrm{ed}$. Englewood Cliffs: Prentice Hall, 1990. 647p.

MARIN, R.; PIZZOLI, G.; LIMBERGER, R.; APEL, M.; ZUANAZZI, J.A.S.; HENRIQUES, A.T. Propriedades nutracêuticas de algumas espécies frutíferas nativas do sul do Brasil. In: RASEIRA, M.C.B.; ANTUNES, L.E.C.; TREVISAN, R.; GONÇALVES, E.D. Espécies frutíferas nativas do sul do Brasil. Pelotas: Embrapa Clima Temperado, 2004. p.107-122. (Documentos, 129) 